\title{
EL PROBLEMA DE LAS DISTINCIONES EN SPINOZA. UNA SUBVERSIÓN CRÍTICA DE DESCARTES
}

\section{THE PROBLEM OF DISTINCTIONS IN SPINOZA. A CRITICAL SUBVERSION OF DESCARTES}

\author{
Mariana DE GAINZA* \\ CONICET, Universidad de Buenos Aires
}

\begin{abstract}
RESUMEN: En este trabajo analizamos la operación de deconstrucción y reelaboración crítica que Spinoza realiza de las distinciones metafísicas heredadas. En particular, acompañando a Deleuze, nos concentramos en la reconceptualización, a la vez sutil y profunda, que la Ética presenta de las tres distinciones que Descartes considera fundamentales para concebir la constitución diversificada del ser: la distinción real, la distinción numérica y la distinción de razón. En la manera en que Spinoza se distancia de Descartes, valiéndose de conceptos cartesianos resignificados, se juega la radicalidad subversiva de su ontología.
\end{abstract}

Palabras Clave: Spinoza, Descartes, ontología, distinciones.

Авsтract: This paper analyzes Spinoza's deconstruction and critical reworking of the inherited metaphysical distinctions. Following Deleuze, we focus on the reconceptualization, subtle and profound at the same time, that the Ethics presents of the three distinctions that are basic for Descartes to conceive the diversified constitution of being: the real distinction, the numerical distinction and the distinction of reason. In the way that Spinoza distances himself from Descartes, using reformulated Cartesian concepts, we can detect the subversive radicalism of his ontology.

KeYwords: Spinoza, Descartes, ontology, distinctions.

* Investigadora en el Instituto Gino Germani, FSOC, UBA. Pte. J. E. Uriburu 950, $6^{\circ}$ piso. C1114AAD, Buenos Aires. marianagainza@gmail.com. 


\section{Introducción}

La disposición estratégica de la filosofía de Spinoza encuentra su soporte ontológico crucial en una teoría de las distinciones, que se despliega como un diálogo confrontativo con las distinciones cartesianas (las cuales, por su parte, constituyen una relectura de la tradición escolástica). Vale la pena acompañar, en relación a esta cuestión, a Gilles Deleuze (1996), quien considera que es precisamente la transformación que realiza Spinoza de las distinciones reconocidas por Descartes la que hace de la Ética demostrada según el orden geométrico una obra particularmente innovadora. La pregunta por las verdaderas distinciones define, así, el núcleo ontológico de la filosofía spinoziana: ¿qué tipo de distinción puede ser llevada al absoluto? O lo que es lo mismo: ¿qué diferenciación es efectiva en el interior del verdadero infinito, esto es, de lo absolutamente infinito como infinito en acto? La Parte I de la Ética puede leerse como la elaboración de la respuesta a este problema, gracias a la cual, según Deleuze, sería posible considerar a Spinoza como el filósofo que ha ido más lejos en la concepción de las distinciones necesarias para una consideración adecuada de la absoluta riqueza del ser.

Un abordaje como éste, que pretende determinar el aspecto subversivo de la ontología spinoziana, dialoga con un conjunto de interpretaciones que ponen el acento en lo que puede caracterizarse como el materialismo de Spinoza ${ }^{1}$. Siguiendo en este punto a F. J. Martínez Martínez, podemos decir, a grandes rasgos, que una perspectiva materialista se funda en la crítica de toda trascendencia, con lo cual se asocia con un pensamiento de la inmanencia; que apunta a una comprensión desmitologizada de la sociedad humana, por lo que se afirma como rigurosamente "terrena"; que defiende un concepto de materia amplio o enriquecido, no pretendiendo afirmar uno de los polos de la oposición materia-espíritu, sino sustituir ese dualismo por la compresión de una única realidad material; y que esa única realidad existente ha de ser considerada en su irreductible pluralidad. Asimismo, los aspectos de la obra de Spinoza que permiten considerarla materialista serían su caracterización del pensamiento y de la extensión como dos dimensiones "entre infinitas otras" diferenciales, simultáneas y correlativas del único Ser; su fundamental concepción del cuerpo, del alma como idea del cuerpo, y del deseo (conatus) como esencia del hombre; su consideración de la sociedad humana como posibilitadora o inhibidora de

${ }^{1}$ Ver, por ejemplo, Vidal Peña (1974), Negri (1993), Martínez Martínez (1988), Tosel (1994). 
las capacidades de autorrealización de los individuos; su lucha contra la teología y su defensa de la democracia como el más natural de los regímenes políticos².

La particularidad de la lectura de Deleuze, en este contexto, consiste en permitirnos visualizar lo que tiene de incisivo la intervención teórica (materialista) de Spinoza en su trabajo concreto con las distinciones, en el interior de un campo filosófico marcado por la relectura cartesiana de la tradición metafísica ${ }^{3}$. La operación spinoziana de subversión de las distinciones cartesianas consiste, sintéticamente, en lo siguiente: la separación de la distinción real de la distinción numérica, y la identificación de la distinción real con una distinción estrictamente cualitativa o formal. Es gracias gracias a ello, dirá Deleuze, que su filosofía permite pensar simultáneamente la multiplicidad y la unidad de la substancia: la distinción real como distinción formal, llevada al absoluto, se vuelve capaz de expresar la diferencia en el ser, esto es, la irreductibilidad formal de una infinidad de atributos en su identidad ontológica. En este artículo, entonces, nos dedicaremos a reconstruir los pasos conceptuales de esta singular teoría spinoziana de las distinciones.

\section{La equivocidad de las distinciones cartesianas}

En sus Pensamientos Metafísicos, Spinoza señala que no tiene sentido demorarse "en el fárrago de distinciones de los peripatéticos" (Spinoza, 1988, 259), siendo suficiente, entonces, partir de la simplificación cartesiana, que admite tres distinciones fundamentales: la distinción real, la distinción modal y la distinción de razón ${ }^{4}$. En la recuperación cartesiana de la escolástica, la distinción real se refiere a la distinción entre substancias, y el criterio para establecerla es que

\footnotetext{
${ }^{2}$ Cf. Martínez Martínez (1988 y 2010).

${ }^{3}$ Asimismo, la interpretación de Deleuze tiene la virtud de permitir arrojar nuevas luces sobre una lectura ya clásica de Spinoza, como la de Martial Gueroult, quien, partiendo de la afirmación de que "es el racionalismo absoluto lo que distingue a Spinoza de los tres otros grandes autores del racionalismo clásico", Descartes, Malebranche y Leibniz (Gueroult, 1968, 9), se dedica a reconstruir el entramado conceptual constitutivo de ese racionalismo absoluto que no admite que ninguna incomprensibilidad apriorística acote o restrinja la potencia del entendimiento humano, inmanente a una fuerza divina de conocer. Puede decirse, entonces, que Deleuze elige una vía propia para determinar en qué consiste ese "absoluto" spinoziano que lo singulariza frente a la tradición (y, en particular, frente a Descartes): la capacidad de pensar ese absoluto, precisamente, como radicalización de las distinciones o diferencias de lo real en su inteligibilidad sustantiva.

${ }^{4}$ La simplificación cartesiana de la abusiva multiplicación de distinciones de la tradición se apoya, a su vez, en Suárez (1960-1967).
} 
una cosa pueda ser concebida clara y distintamente sin el concepto de otra; la distinción modal se da entre una substancia y un modo (en cuanto manera de ser o de actuar de esa substancia, que sin ella no puede ser ni ser concebido, aunque la substancia sí pueda ser concebida sin su modo), y entre modos de la misma substancia; la distinción de razón, finalmente, se establece entre una substancia y su atributo, que es aquello por lo cual la substancia es conocida clara y distintamente (no siendo posible conocer una substancia sino a través de su atributo). Lo que permite conocer una substancia y distinguirla de otras es su atributo principal, "que constituye su naturaleza y su esencia y del cual dependen todos los otros" (Descartes, 1995, 53).

A pesar de ser cartesiana la concepción de que el ser se divide en substancia y modos (de tal manera que todo lo que existe, o es en sí, o es en otra cosa) la manera en que Spinoza comprende esa distinción ontológica es nítidamente divergente. Debido a que Descartes conserva la noción de substancia como sujeto de inherencia de predicados, su concepción de los atributos y los modos acaba siendo equívoca. Como lo dice de manera explícita en el $\$ 56$ de los Principios: "cuando hablo de forma o modo no entiendo otra cosa que lo que denomino en otros lugares atributo o cualidad" (Descartes, 1995, 55). Un atributo puede ser considerado como cualidad en tanto califica la substancia, pero también como modo en tanto la diversifica; de manera que "el atributo constituye la esencia de la substancia que califica, pero no en menor medida constituye también la esencia de los modos que refiere a las substancias de igual atributo" (Deleuze, 1996, 26). Esto significa que la distinción de razón, que implicaba que únicamente por abstracción el atributo principal de una substancia podía ser diferenciado de ella, vale como distinción modal cuando el atributo es considerado como constitutivo de la esencia de los modos, debiendo ser, entonces, necesariamente distinguido de dicha substancia (substrato invariable, que no admite ser considerado como algo accidental); pero la condición de no hacer de él algo subsistente por sí; a condición de hacer de él solamente la propiedad que la substancia tiene de cambiar (es decir, de tener figuras variables [cuando se considera la extensión] o pensamientos diversos [cuando se trata del atributo pensamiento]) (Deleuze, 1996, 25-26). A partir de esta base se

\footnotetext{
5 "Hay que recordar lo que dijo Descartes en los Principios de Filosofía, a saber, que en la naturaleza real no existen más que las substancias y sus modos, de donde se deduce la triple distinción de las cosas: real, modal y de razón" (Spinoza, CM, G, 257-258; Spinoza, 1988, 257-258). En adelante, las citas de Spinoza remitirán a la edición Gebhardt (G), según las siguientes abreviaturas: CM (Cogitata Metaphysica, "Pensamientos metafísicos"); E (Ethica ordine geometrico demonstrata, "Ética demostrada según el orden geométrico").
} 
entiende que, para Descartes, puedan darse substancias con el mismo atributo, esto es, substancias que comparten el predicado -que debía ser, en principio, el que nos permitiría conocer distintamente su esencia. Lo que conduce al siguiente problema: ¿cómo distinguir entre sí esas substancias? Su distinción, como es claro, no puede darse por el atributo, pues es dicho atributo el que se supone igual al de otras substancias que también se caracterizan por poseerlo. La distinción debería darse, entonces, por los modos. Pero los modos son considerados como afecciones accidentales, variables e inestables; de manera que, nuevamente, debe apelarse al sustrato fijo o substancia a la que pertenecen en cuanto modificaciones. Lo cual nos reenvía, otra vez, a la pregunta: ¿cómo identificar a esa substancia modificada, que debe ser distinta de otras substancias modificadas de otras maneras? La distinción real entre esas substancias de igual atributo, o sea, la distinción que las convierte en individuos independientes, debe ser, entonces, una distinción numérica. La distinción modal es considerada, de esta manera, como real, a partir de la identificación de la distinción real con la distinción numérica. Veamos por qué esta solución es inadmisible desde la perspectiva de Spinoza.

\section{La intervención de Spinoza. La unicidad substancial y las distinciones}

La distinción propiamente spinoziana comienza a ser formulada en la proposición 4 de la parte I de la Ética:

Dos o más cosas distintas se distinguen entre sí, o por la diversidad de los atributos de las substancias o por la diversidad de las afecciones de las mismas. Demostración: Todo lo que es, o es en sí, o en otra cosa, esto es, fuera del entendimiento nada se da excepto las substancias y sus afecciones. Por consiguiente, nada hay fuera del entendimiento que sea apto para distinguir varias cosas entre sí, salvo las substancias o, lo que es lo mismo, sus atributos y sus afecciones. (E, I, P4; G, II, 47)

\footnotetext{
${ }^{6}$ De aquí en adelante, para las citas de la Ética $(E)$ se indicarán las partes en números roma$\operatorname{nos}(E, \mathrm{I}$; II, etc.); las definiciones y las proposiciones en arábigos ( $E$, I, def. 3; $E$, I, P 20); señalándose con abreviaturas las explicaciones (expl.), los axiomas (ax.), las demostraciones (dem.), los corolarios (cor.), los escolios (esc.), los lemas (lem.) y los postulados (post.). Las citas en español son de la traducción de la Ética de Vidal Peña, consignada en la Bibliografía; y la paginación señalada remite a la Edición Gebhardt (en este caso: G, II, 47).
} 
Spinoza define, en primer lugar, el ámbito de lo que se distingue ontológicamente (lo que se distingue, se distingue "por la diversidad de los atributos de las substancias o por la diversidad de las afecciones de las mismas"), delimitándolo como aquel que involucra distinciones reales, y no distinciones de razón (pues éstas, dándose sólo en el entendimiento, no existen como verdaderas divisiones en la naturaleza). A partir de ello, puede consolidar su propio terreno de argumentación por fuera de las ambigüedades cartesianas ${ }^{7}$. "En el orden natural no pueden darse dos o más substancias de la misma naturaleza, o sea, con el mismo atributo" (E, I, P 5; G, II, 48). ¿Qué significa concretamente esta proposición que subvierte lo que podía suponerse, inicialmente, como una pura apropiación de las distinciones de Descartes? "Si se diesen varias substancias distintas -dice la demostración de la P 5- deberían distinguirse entre sí, o en virtud de la diversidad de sus atributos, o en virtud de la diversidad de sus afecciones" (pues, como estableció la P4, tan sólo atributos y afecciones sirven para distinguir entre sí a los seres). Y continúa:

Si se distinguiesen por la diversidad de sus atributos, tendrá que concederse que no hay sino una con el mismo atributo. Pero si se distinguiesen por la diversidad de sus afecciones, entonces, como es la substancia anterior por naturaleza a sus afecciones, dejando, por consiguiente, aparte esas afecciones, y considerándola en sí, esto es, considerándola en verdad, no podrá ser pensada como distinta de otra, esto es, no podrán darse varias, sino sólo una. Q.E.D. (E, I, P 5, dem.; G, II, 48)

Si hubiesen dos substancias distintas (nótese el condicional), tendrían que distinguirse por alguno de los dos únicos criterios admitidos para la diferenciación ontológica de las cosas. Si "atributo" es lo que constituye la naturaleza de una substancia, es lo que necesariamente diferencia su esencia de cualquier otra cosa; por eso, no puede haber más que una substancia con el mismo atributo: dos o más substancias con el mismo atributo no serían dos o más substancias, sino una misma substancia, ya que sólo el atributo hace de una substancia algo distinto. $\mathrm{Si}$ "afección" es lo que es en otra cosa por medio de la cual debe concebirse, una substancia, que por naturaleza es anterior a sus afecciones, no puede depender de ellas para distinguirse; sus afecciones -necesariamente "derivadas"-

\footnotetext{
${ }^{7}$ Debido a lo cual, suele generalmente reconocerse que, si bien Spinoza "toma su punto de partida en un dominio cartesiano", sin embargo, lo que "acepta de Descartes, lo que rechaza, y principalmente, lo que acepta para volverlo contra Descartes" (Deleuze, 1996, 24) hace que su trabajo filosófico pueda ser leído como una subversión crítica de los principios cartesianos.
} 
no pueden servir para definirla tal como es "en sî" o "en verdad", de ahí que tampoco puedan ser distinguidas dos o más substancias por sus modos. Pero si los únicos criterios válidos para distinguir los seres no sirven para distinguir entre sí varias substancias, la conclusión que se impone es que no puede haber varias o múltiples substancias, sino que sólo existe una única substancia.

La admisión de la posibilidad de la existencia de una multiplicidad de substancias (dos o más) fue, en realidad, el recurso del que Spinoza se valió para deslegitimar completamente a la distinción numérica como criterio válido para la distinción ontológica. Y la necesidad de esa exclusión está directamente conectada con las consecuencias fundamentales que genera: una substancia no puede ser producida por otra (E I, P 6; G, II, 48), esto es, no puede ser "creada" (pues para que una cosa produzca otra, ambas deben tener algo en común siendo precisamente ese supuesto el que fue eliminado gracias a la demostración de que no existen substancias con el mismo atributo). De ahí que a la naturaleza o esencia de una substancia pertenezca el existir -es decir, que sea causa sui- y que deba ser necesariamente infinita ( $E$ I, P 7 y P 8; G, II, 49).

Como queda claro en el segundo escolio de la $E$ I, P 8, eliminar las ambigüedades en relación a la "división del ser" y, sobre todo, dejar de considerar al número como operador fundamental de la distinción real, era indispensable para que Spinoza distinguiera su propia iniciativa filosófica de la tradición metafísica y teológica, cuyos postulados sostienen, de manera general, un compromiso firme con el sentido común. Sin duda, dice Spinoza, la idea de que una substancia no puede ser producida o creada, sino que es causa de sí, ha de ser de difícil aceptación para aquellos que

juzgan confusamente de las cosas y no están acostumbrados a conocerlas por sus primeras causas; $y$ ello porque no distinguen entre las modificaciones de las substancias y las substancias mismas, ni saben cómo se producen las cosas. De donde resulta que imaginen para las substancias un principio como el que ven que tienen las cosas naturales; pues quienes ignoran las verdaderas causas de las cosas lo confunden todo, y, sin repugnancia mental alguna, forjan en su espíritu árboles que hablan como los hombres, y se imaginan que los hombres se forman tanto a partir de piedras como de semen, y que cualesquiera formas se transforman en otras cualesquiera. Así también, quienes confunden la naturaleza divina con la humana atribuyen fácilmente a Dios afectos humanos, sobre todo mientras ignoran cómo se producen los afectos 
en el alma. Pero si los hombres atendieran a la naturaleza de la substancia, no dudarían un punto de la verdad de la Proposición 7; muy al contrario, esta Proposición sería para todos un axioma, y se contaría entre las nociones comunes. Pues por substancia entenderían aquello que es en sí y se concibe por sí, esto es, aquello cuyo conocimiento no precisa del conocimiento de otra cosa. En cambio, por modificaciones entenderían aquello que es en otra cosa, y cuyo concepto se forma a partir del concepto de la cosa en la que es. ( $E$ I, P 8, esc.2; G, II, 49-50)

Confusión de substancias y modificaciones, confusión acerca de las causas que producen las cosas, confusión de la naturaleza divina con la humana. En esa red de conexiones mal establecidas y naturalezas incomprendidas se encuentran entrampados aquellos que no saben operar las distinciones necesarias, y que no comprenden, en consecuencia, que "sólo hay una substancia de la misma naturaleza”. La distinción numérica es, por ello, inaplicable a la substancia. Y este argumento es el que Spinoza continúa expandiendo en el mismo escolio: si en la naturaleza existe un determinado número de individuos, es necesario que exista necesariamente una causa que explique que se dé ese número de individuos y no otro, de tal manera que

si, por ejemplo, existen en la naturaleza veinte hombres (que, para mayor claridad, supongo existen a un tiempo, y sin que en la naturaleza haya habido otros antes), no bastará (para dar razón de por qué existen veinte hombres) con mostrar la causa de la naturaleza humana en general, sino que además habrá que mostrar la causa en cuya virtud no existen ni más ni menos que veinte, puesto que debe haber necesariamente una causa de la existencia de cada uno. Pero esta causa no puede estar contenida en la naturaleza humana misma, toda vez que la verdadera definición del hombre no implica el número veinte; $y$ de esta suerte, la causa por la que esos veinte hombres existen, y, consiguientemente, por la que existe cada uno, debe darse necesariamente fuera de cada uno de ellos; y por ello es preciso concluir, en absoluto, que todo aquello de cuya naturaleza puedan existir varios individuos, debe tener necesariamente, para que existan, una causa externa. ( $E$ I, P 8, esc. 2; G, II, 51)

Ha de tomarse como una evidencia empírica el hecho de que, en cierto lugar y tiempo, exista un determinado número de individuos (para el caso, veinte hombres), incontestablemente discernibles entre sí por cuestiones de física 
elemental: ellos no pueden "superponerse", y ocupar simultáneamente la misma porción extensa, fusionando las materias que los componen; cada uno tiene, por el contrario, su propia forma diferenciada que hace de su constitución, precisamente, una constitución individual. Por eso son percibidos como individuos, ¿quién habría de dudarlo? Lo que no quiere decir, sin embargo, que sean substancias. Pues, precisamente, la substancia, por su misma naturaleza (ser en sí y por sí concebida) no admite ninguna determinación externa, por lo cual es incompatible con la distinción numérica que informa que algo (una clase $\mathrm{X}$ de cosas -como determinación cualitativa-) existe en un número mayor o menor (un número $Y$ de individuos -como determinación cuantitativa-). La substancia no es "una”, pero tampoco existen dos, ni veinte, ni infinitas substancias. La substancia es única, porque tiene en sí misma la razón de su existencia, y por eso mismo es infinita. Esos veinte hombres, en cambio, pueden existir como veinte, porque existen causas fuera de ellos que, explicando la existencia de cada uno, explican asimismo la existencia de todos en un grupo de veinte. Es por eso que "todo aquello de cuya naturaleza puedan existir varios individuos, debe tener necesariamente, para que existan, una causa externa". ${ }^{8}$ De esta manera, las cartesianas "substancias" de un mismo atributo, distinguibles sólo numéricamente, son incompatibles con la definición de substancia. Constituyen, entonces, un caso paradigmático de confusión de la substancia con sus modificaciones. A lo que se suma el hecho de que, si bien el número puede ser aplicado a los modos, constituye sin embargo una forma sumamente inadecuada para distinguirlos: agrupándolos en una clase a partir de su semejanza (un género, un "mismo atributo", que se coloca en el lugar de la esencia), e individualizándolos a partir de rasgos puramente externos. El número, cómplice de la clasificación genérica de las cosas, nada nos enseña sobre sus verdaderas esencias.

\footnotetext{
${ }^{8}$ Queda claro que lo que vale para todos los individuos, vale también para el hombre. Pero es especialmente difícil para la tradición considerar al hombre de la misma manera que al resto de los individuos de la naturaleza. Así, lo que aquí concierne a los individuos naturales en general (y es sólo ejemplificado con el caso de los veinte hombres), será referido al hombre como realidad singular en la parte II de la Ética: "A la esencia del hombre no pertenece el ser de la substancia, o sea, no es una substancia lo que constituye la forma del hombre" ( $E$, II, P 10; G, II, 92). La demostración de esta proposición será reforzada con lo que aquí, en la $E$, I, se dice acerca de la incompatibilidad entre la existencia numéricamente múltiple y el ser de la substancia: "Esta Proposición se demuestra también a partir de la Proposición 5 de la Parte I, a saber: que no hay dos substancias de la misma naturaleza. Pero, dado que pueden existir varios hombres, entonces no es el ser de la substancia lo que constituye la forma del hombre. Esta Proposición es evidente, además, en virtud de las demás propiedades de la substancia, a saber: que la substancia es, por naturaleza, infinita, inmutable, indivisible, etc., como todos pueden ver fácilmente" (E, II, P 10, esc.; G, II, 93).
} 


\section{Un pensamiento sin garantías. La reformulación de la idea de atributo}

Las distinciones cartesianas presentan -además del mencionado problema de la consideración de la distinción numérica como una distinción real- otra dificultad, que concierne directamente a la distinción real (Deleuze, 1996, 2627). Si dos cosas pueden ser realmente distinguidas, en el caso de Descartes, ello se debe a que una puede ser concebida clara y distintamente sin recurrir al concepto de la otra. Eso no quiere decir que las cosas concebidas como realmente distintas se confundan con las cosas que realmente se distinguen, pues, en efecto, las cosas reales son diferentes de las ideas que las representan. En ese sentido, Descartes reconoce adecuadamente que la distinción real se refiere a las cosas mismas, independientemente de las operaciones mentales mediante las que dichas distinciones son pensadas. Y sin embargo, ¿qué es lo que permite asegurar que aquello que se concibe como realmente distinto (es decir, sin recurrir al concepto de ninguna otra cosa) es en la realidad distinto? Es decir, ¿cómo afirmar la verdad de nuestras ideas? He aquí el gran problema cartesiano, que se resuelve mediante el recurso al Dios no engañador, "garantía" de dicha correspondencia: Dios no se ajustaría a las imágenes de omnipotencia, sabiduría y bondad que se le asocian, si no crease las cosas tal como las ideas claras y distintas las entienden. Esto quiere decir, básicamente, que la distinción real cartesiana no posee en sí la razón de lo distinguido, dándose dicha razón en un más allá trascendente, el Dios creador, que es el que nos hace pasar de las substancias concebidas como realmente distintas a las substancias efectivamente distinguidas en la realidad. Esa exterioridad o trascendencia del principio causal y explicativo es el que hace de ese "pasaje" de las ideas a las cosas (que permite pensar a las ideas como ideas verdaderas, y a las cosas como cosas reales) consista en una división de las cosas reproduciendo las distinciones que la razón establece. Así, si concebimos el cuerpo distintamente, y también distintamente el alma, han de ser dos substancias diferentes (de donde surgen, consecuentemente, todas las dificultades del cartesianismo para concebir su unión).

Ahora bien, la concepción spinoziana de la distinción real se da, otra vez, operando un fundamental cambio de posición. También para Spinoza lo que es realmente distinto debe concebirse por sí; por lo cual, el campo de la distinción real es el de los atributos. Como dice la $E$ I, P 10 (G, II, 51): "Cada atributo de una misma substancia debe concebirse por sî" (pues siendo el atributo lo que constituye la esencia de una substancia "la realidad que es en sí y se concibe por sí”, dicha esencia, es decir, el atributo que la constituye, debe concebirse por sí). 
Entretanto, si no se registra aquí -literalmente hablando- diferencia alguna con el criterio cartesiano, su sentido cambia fundamentalmente. En Descartes, la distinción real de lo que se concibe por sí debe necesariamente ir acompañada por la mencionada división en las cosas; los atributos spinozianos, en cambio, no admiten ninguna división de esa índole: no pueden pensarse como lo que tendrían en común grupos diferentes y separados de seres. Por eso, su concepción de los atributos debe ser considerada conjuntamente con su crítica de las nociones que operan mediante la abstracción de rasgos característicos. De tal manera que los atributos no pueden ser considerados, por ejemplo, como las diferencias específicas que organizarían a los seres, a partir de un género supremo y a través de diversificaciones sucesivas. "Solemos reducir todos los individuos de la naturaleza a un único género, que llamamos 'generalísimo', a saber: la noción de 'ser', que pertenecería absolutamente a todos los individuos de la naturaleza”, leemos en el Prefacio de la Ética, IV (G, II, 207). El 'ser' o género supremo es un término trascendental, y los trascendentales reciben el mismo tratamiento crítico, por parte de Spinoza, que las nociones llamadas universales. Se trata de nociones que "remiten a ideas sumamente confusas", pues la mente sólo puede imaginar de manera distinta la cantidad de cuerpos cuyas imágenes su propio cuerpo -finito y limitado- sea capaz de formar simultáneamente; de tal forma que si ese número de imágenes "abarcables" es ampliamente sobrepasado, las imágenes corporales se mezclen y se confundan, y

el alma imaginará asimismo todos los cuerpos confusamente, sin distinción alguna, y los considerará agrupándolos, en cierto modo, bajo un solo atributo, a saber: bajo el atributo de "Ser", de "Cosa", etc. [...] De causas similares han surgido también las nociones llamadas universales, como "hombre", "caballo", "perro", etc., a saber: porque en el cuerpo humano se han formado simultáneamente tantas imágenes - por ejemplo- de hombres, que la capacidad de imaginar queda, si no del todo, sí lo bastante desbordada como para que el alma no pueda imaginar las pequeñas diferencias entre los seres singulares (como el color o el tamaño de cada uno, etc.), ni tampoco el número preciso de ellos, y sólo imagine de un modo distinto aquello en que todos concuerdan en la medida en que afectan al cuerpo (ya que es en virtud de ello como cada cosa singular afecta sobre todo al cuerpo), y eso es lo que el alma expresa con la palabra "hombre", predicándolo de infinitos seres singulares. (E, II, P 40 esc. 1 ; G, II, 121)

Resaltemos, entonces, lo que aquí nos interesa: lo que la mente realiza cuando intenta imaginar las cosas en su máxima generalidad es "agruparlas bajo 
un solo atributo", de tal forma que el conjunto de todas las cosas, pensadas sin distinción alguna, a partir de la máxima confusión de las imágenes en el cuerpo excedido en su capacidad de formar imágenes distinta y simultáneamente, recibe el nombre de "Ser" como noción generalísima. Las especies se distinguen, en relación a ese "Ser" -reductor de toda la variedad de lo existente a un único atributo común- agregando atributos, de manera que puedan distinguirse entre los seres, progresivamente, los seres vivos, los vertebrados, los mamíferos, el "hombre", el "caballo" el "perro", etc. Pero la especificación (que procede por diferencias genéricas) sigue siendo relativa a una capacidad imaginativa "lo bastante desbordada como para que el alma no pueda imaginar las pequeñas diferencias entre los seres singulares". Lo que se hace, en verdad, mediante tal procedimiento, es otorgarle realidad substancial a una mera distinción de razón. Un término universal como "hombre", por ejemplo, que se predica de infinitos seres singulares, sólo señala algún rasgo en el cual todos concuerdan en la medida en que afectan al cuerpo (y cuyo reconocimiento general se funda sobre cierta arbitrariedad -pues "el cuerpo" quiere decir, más bien, "los cuerpos", de manera que la imagen que diversos hombres formen del "hombre" diferirá, según cuál sea la constitución de cada uno y según cómo cada uno de ellos haya sido afectado por aquella realidad a la que la palabra "hombre" refiere"). Por eso, Spinoza se distancia de esa forma de comprender los atributos como operadores de la distribución del "ser" en clases diferenciadas (según signos característicos ${ }^{10}$ ), que clasificarán a su vez a los individuos (numéricamente distinguidos): se trata de una manera impropia de pensar las distinciones reales. Así, la crítica a la

\footnotetext{
${ }^{9}$ Según las palabras de Spinoza: "esas nociones [universales] no son formadas por todos de la misma manera, sino que varían en cada cual a tenor de la cosa por la que el cuerpo ha sido más a menudo afectado, y que el alma imagina o recuerda más fácilmente. Quienes, por ejemplo, hayan reparado con admiración, más que nada, en la bipedestación humana, entenderán por la palabra 'hombre' un animal de posición erecta; pero quienes están habituados a considerar otra cosa, formarán de los hombres otra imagen común, a saber: que el hombre es un animal que ríe, un bípedo sin plumas, un animal racional, y, de esta suerte, formará cada cual, según la disposición de su cuerpo, imágenes universales acerca de las demás cosas. Por ello no es de extrañar que hayan surgido tantas controversias entre los filósofos que han querido explicar las cosas naturales por medio de las solas imágenes de éstas.” ( $E$, II, P 40, esc.1; G, II, 121).

${ }^{10} \mathrm{La}$ imposibilidad de comprender, desde una perspectiva spinoziana, los atributos como "signos" que servirían para reconocer diversas substancias es explícitamente enunciada al final del escolio de la $E$, I, P 10. Allí, dice Spinoza: "Si alguien pregunta ahora en virtud de qué signo podríamos reconocer la diversidad de las substancias, lea las Proposiciones siguientes, las cuales muestran que en la naturaleza no existe sino una única substancia, y que ésta es absolutamente infinita, por lo que dicho signo sería buscado en vano" ( $E, \mathrm{I}, \mathrm{P} 10$, esc.; G, II, 52).
} 
distinción real como división del ser es el complemento necesario de la crítica a la distinción numérica considerada por la tradición como real.

\section{La diversidad absoluta de una única realidad. EI ser de lo complejo}

¿Cuál es, entonces, el estatuto de los atributos spinozianos, que no dividen el ser, pero tampoco pueden ser entendidos como meras distinciones de razón?

Aunque dos atributos se conciban como realmente distintos -esto es, uno sin intervención del otro-, no podemos, sin embargo, concluir de ello que constituyan dos entes o dos substancias diversas, ya que es propio de la naturaleza de una substancia que cada uno de sus atributos se conciba por sí, supuesto que todos los atributos que tiene han existido siempre a la vez en ella, y ninguno ha podido ser producido por otro, sino que cada uno expresa la realidad o ser de la substancia. Por tanto, dista mucho de ser absurdo el atribuir varios atributos a una misma substancia, pues nada hay más claro en la naturaleza que el hecho de que cada ente deba concebirse bajo algún atributo, y cuanta más realidad o ser tenga, tantos más atributos tendrá que expresen necesidad, o sea, eternidad e infinitud; y, por tanto, nada más claro tampoco que el hecho de que un ente absolutamente infinito haya de ser necesariamente definido como el ente que consta de infinitos atributos, cada uno de los cuales expresa una determinada esencia eterna e infinita. ( $E, \mathrm{I}, \mathrm{P}$ 10 , esc.; G, II, 52)

Los atributos son realmente distintos y, sin embargo, todos expresan la esencia indivisible de una única substancia; por eso, la extensión y el pensamiento no pueden ser considerados como dos entes o dos substancias diversas. Los atributos son expresiones simultáneas de una única naturaleza substancial infinita ("todos han existido siempre a la vez en ella, y ninguno ha podido ser producido por otro"). Por lo cual, insiste Spinoza, "dista mucho de ser absurdo el atribuir varios atributos a una misma substancia". Si la naturaleza o esencia de cada ente debe considerarse bajo algún atributo, cuanto más realidad o ser se reconozca a un ente, más atributos deben expresarlo. Por eso, la única substancia debe ser concebida, en su infinitud, gracias a una infinidad de atributos. Se ve, de esta manera, que la realidad infinita no es tal por subsumir un número infinito de seres, sino por estar constituida por una diversidad absoluta, desde el punto de vista cualitativo. Tener más realidad quiere decir, para Spinoza, tener 
mayor riqueza o complejidad; de manera que el "más" no remite a un "más de lo mismo", sino a "más diferencias": cuantas más diferencias internas reúne un ser, mayor es su realidad o perfección. Conocemos la distinción real que nuestro propio ser finito (constituido por un cuerpo y una mente) envuelve: la diferencia irreductible entre el pensamiento y la extensión. Pero el hombre es sólo una parte entre otras de la naturaleza, de manera que su constitución diversa no puede agotar la diversidad de lo real; por eso, la substancia spinoziana se constituye no sólo de la diferencia cualitativa que compete directamente al ser humano, sino de una infinidad de diferencias irreductibles.

Los atributos en cuanto constituyentes de la naturaleza de la substancia no son, entonces, caracteres abstraídos de las cosas reales, no son categorías o nombres que se aplicarían externamente a un contenido separado de ellas, no son propiedades ${ }^{11}$ que se predican de un sujeto. Por constituir la esencia, la expresan en su propio ser concreto (no son sus signos, representaciones o manifestaciones externas). Los atributos son realidades que, en virtud de su infinitud, coinciden o son idénticas, cada una de ellas, a la "totalidad": la substancia se expresa entera en cada uno de sus atributos ${ }^{12}$ (por eso, tampoco pueden ser considerados como partes $^{13}$ o expresiones parciales). Son las naturalezas o esencias cualitativas o

\footnotetext{
${ }^{11}$ Las propiedades, en efecto, pertenecen a algo sin explicar lo que ese algo es. No constituyen su esencia, sino que se afirman de aquello que la constituye. Por eso, si los atributos que constituyen la substancia son la extensión y el pensamiento, sus propiedades son la infinitud, la eternidad, la simplicidad, la indivisibilidad, la inmutabilidad la perfección, la realidad o existencia (en virtud de lo cual, puede decirse que tanto la extensión como el pensamiento son infinitos, eternos, simples e indivisibles, etc.).

12 "En tanto se consideren las cosas como modos de pensar, debemos explicar el orden de la naturaleza entera, o sea, la conexión de las causas, por el solo atributo del Pensamiento, y en tanto se consideren como modos de la Extensión, el orden de la naturaleza entera debe asimismo explicarse por el solo atributo de la Extensión, y lo mismo entiendo respecto de los otros atributos" (E, II, P 7, esc.; G, II, 90).

${ }^{13}$ Considerar a los atributos como "partes" es una de las confusiones, según han reconocido varios comentadores, a las que puede conducir la interpretación de Gueroult de las primeras proposiciones de la Ética, como "construcción" de la substancia infinita a partir de las "substancias de un atributo". Esa "anterioridad" de los elementos de la construcción respecto a aquello que es construido por su medio, hace que sea posible pensar los atributos como partes diferentes que, adicionadas, conforman un todo. Sin embargo, la identidad de los atributos y la substancia y la simultaneidad de su existencia constituyéndola impide suponer la divisibilidad del todo que esa interpretación implícitamente deja subsistir. La ontología spinoziana no admite la construcción del todo a partir de las partes, ni de lo complejo a partir de lo simple: el todo (simplemente entendido como todo) no es otra cosa que su propia constitución compleja.
} 
formas de $\operatorname{ser}^{14}$ realmente distintas que constituyen ese todo substancial y que, sin medida común alguna entre sí, son simplemente incomparables. Son los atributos, en definitiva, los que hacen de la realidad algo que es, en sí mismo, absolutamente distinto de sí.

\section{La diferencia (in)finita. Modos distintos de ser}

La distinción real entre los atributos está, a su vez, implicada por los modos que cada atributo produce en sí como sus modos de ser, es decir, como las afecciones de esa potencia causal cualitativamente diferenciada. Por eso, la distinción de la extensión y el pensamiento explica que sus modos respectivos -los cuerpos y las ideas de esos cuerpos- sean efectivos sólo en el interior de su propio orden de realidad. Porque la distinción real entre las esencias de la substancia se prolonga en la distinción modal de sus afecciones, se explica que no sea lícito mezclar o confundir los cuerpos y las ideas, suponiendo por ejemplo que una mente pueda actuar sobre un cuerpo, determinándolo a producir ciertos efectos (que serían, en ese caso, engendrados por una intención o una decisión de la mente), o a la inversa, que un cuerpo pueda ser causa eficiente de ciertas ideas (que serían, por su parte, empiricamente generadas, como si fueran reflejos de una realidad material o extensa de la que serían enteramente dependientes). Pero al mismo tiempo, comprender la distinción supone también comprender que aquello que se distingue son dos modos de ser constitutivos de la misma cosa, es decir, el mismo individuo: en el caso del hombre, un cuerpo singular (modo del atributo extensión) y la idea de ese cuerpo (modo del atributo pensamiento) son la misma cosa, considerada bajo dos perspectivas diferenciadas. Nuevamente, lo que es idéntico (es decir, lo que es una misma cosa) consiste en la coincidencia con su propia distinción constitutiva (o sea, consiste en la diferencia entre sus propios modos de ser-cuerpo e idea-).

\footnotetext{
${ }^{14}$ Es por ese carácter puramente cualitativo de la distinción real spinoziana que Deleuze la asocia con la distinción que representó la gran innovación de Duns Escoto frente al repertorio escolástico: la distinción actual formal por la naturaleza de la cosa (actualis formalis ex natura rei). Se refiere a una diferencia que, precisamente, ni divide al ser, ni es mero resultado de una operación mental. Por eso, es una distinción que permite diferenciar, al interior de lo que es absolutamente unitario, formas que, si bien se presentan como idénticas a la cosa, no pueden equipararse entre sí. La distinción formal permite, entonces, concebir una esencia que, al mismo tiempo, es simple (indivisible en partes componentes) y compleja (constituida de diversas formas cualitativamente diferenciadas).
} 
A partir de ello, ¿qué es la distinción modal spinoziana? Los modos o afecciones no se distinguen realmente entre sí, lo cual para sus eventuales interlocutores Spinoza lo sabe bien- es especialmente difícil de entender en el caso de la materia o la substancia extensa, pues todo el mundo es "propenso por naturaleza" a dividir la cantidad. Además de los argumentos contra la divisibilidad que Spinoza elabora al analizar la habitual y generalizada confusión entre modos de imaginar (o entes de razón) y seres reales (cf., en particular, la Carta 12 a Meyer), Spinoza se sirve, en la Etica, de un argumento que debería ser válido para los cartesianos, la ausencia de vacío en la naturaleza:

Ciertamente, si hay cosas que son realmente distintas entre sí, una puede existir y permanecer en su estado sin la otra. Pero como en la naturaleza no hay vacío (...), sino que todas sus partes deben concurrir de modo que no lo haya, se sigue de ahí que esas partes no pueden distinguirse realmente, esto es, que la substancia corpórea, en cuanto substancia, no puede ser dividida (...) Lo cual estará bastante claro para todos los que hayan sabido distinguir entre imaginación y entendimiento: sobre todo, si se considera también que la materia es la misma en todo lugar, y que en ella no se distinguen partes, sino en cuanto la concebimos como afectada de diversos modos, por lo que entre sus partes hay sólo distinción modal, y no real. (E, I, P 15, esc.; G, II, 59)

Este razonamiento, en el contexto de la Parte I de la Ética, se plantea para probar que la extensión o la substancia corpórea constituye la naturaleza de Dios. La extensión es tan digna de la naturaleza divina como el pensamiento, pues ninguno de los argumentos esgrimidos habitualmente para separarla de la substancia (por ejemplo, el de su finitud y corruptibilidad) es válido, dado que se sostienen sobre un supuesto falso: el de que la substancia corpórea se compone de partes y, por ello, es múltiple y divisible ${ }^{15}$. Todo tipo de realidad diferenciada que sea concebible por sí (atributo), constituye necesariamente la naturaleza de Dios, y las cosas que se derivan de la potencia causal asociada a dicha realidad (modos) son necesariamente en Dios, en cuanto es constituido por tal atributo o esencia especial. La inmanencia de la causa sui es lo que hace de los atributos fuerzas de producción realmente distintas, de las que se siguen infinitos efectos que, en cada orden cualitativo de determinación, se distinguen entre sí modalmente.

\footnotetext{
${ }^{15}$ La división, sin embargo, es posible, en virtud de la abstracción que ayuda a imaginar las cosas más fácilmente. Por eso, a la vez que Spinoza concluye el escolio diciendo que "no hay razón alguna para decir que Dios padezca en virtud de otra cosa, o que la substancia extensa sea indigna de la naturaleza divina", admite, no obstante, que "se la suponga divisible, con tal que se conceda que es eterna e infinita” ( $E$, I, P 15, esc.; G, II, 60).
} 


\section{Conclusiones. La distinción ontológica y la potencia del pensamiento}

Para terminar con este contrapunto relativo a la teoría de las distinciones, ¿cómo se da finalmente, en Spinoza, la coincidencia de la distinción real y la distinción epistemológica? Es decir, ¿cómo se explica que las cosas sean conocidas, en sus diferencias, tal como realmente son? Si, como dijimos, la distinción real cartesiana no posee en sí la razón de lo distinguido, sino que la constituye gracias a un apelo trascendente, la distinción real spinoziana, en cambio, debe incluir en sí misma su ratio. La causalidad inmanente, en este sentido, implica un cambio de fundamento. "Debe asignársele a cada cosa una causa, o sea, una razón [causa seu ratio], tanto de su existencia, como de su no existencia", dice Spinoza en E, I, P 11, dem 2., de tal manera que "por ejemplo, si un triángulo existe, debe darse una razón o causa por la que existe, y si no existe, también debe darse una razón o causa que impide que exista, o que le quita su existencia" ( $E, G, I I, 52-53)$. Como la causa se identifica con la ratio, lo que es causa de sí tiene necesariamente en sí mismo la razón que lo explica, mientras que lo que es causado por otro, encuentra en esa otra causa la razón por la que es y existe de cierta manera y no de otra. La causa es, por eso, tanto principio de producción o efectividad ( $\mathrm{y}$ en ese sentido, principio de realidad), como principio de inteligibilidad (o principio de conocimiento verdadero de esa realidad) ${ }^{16}$. La concepción spinozista de la inteligibilidad, de esta manera, parte de la identificación de una esencia absolutamente infinita con la realidad que tiene la potencia para auto-causarse o auto-producirse. Esa esencia contiene todas las propiedades que se siguen necesariamente de su definición; y esa causa, que produce una infinidad de cosas en infinitos modos, las explica a todas ellas como sus propios efectos. En ese sentido, esa causa y esa esencia son la misma

\footnotetext{
${ }^{16}$ Como lo sintetiza muy bien Marilena Chaui: "La reformulación spinoziana del concepto de causa atiende a tres exigencias principales: en primer lugar, garantizar que el adagio aristotélico "Conocer es conocer por la causa" sea elevado a la posición del principio de razón y de inteligibilidad de lo real (lo que explica que la primera definición de la Ética sea la de la causa de sí); en segundo lugar, garantizar que la causa de sí y la causa eficiente inmanente posean el mismo sentido, de tal forma que se pueda sostener no sólo la inteligibilidad plena de la realidad, sino también la identidad entre causa y ratio, entre la acción que causa un efecto y el principio del cual se siguen consecuencias; en tercer lugar, garantizar consecuentemente que la necesidad es la manera de ser de todas las cosas, porque para todas ellas hay una causa: Dios, o la Naturaleza Naturante, es necesario por su esencia y potencia; los modos, o la Naturaleza Naturada, son necesarios por la fuerza de su causa, o sea (sive), por su razón" (Chaui, 1999, 71, la traducción es mía).
} 
cosa: la causa es la ratio, que explica todos sus efectos permitiendo concebirlos como afecciones de sus atributos -esto es, como las propiedades de una cierta esencia-. Ninguna necesidad de recurrir, entonces, a una garantía trascendente de la inteligibilidad: ésta se encuentra articulada en el mismo concepto de causa de sí. Causa sui sive ratio sui que, posteriormente, en la proposición 7 de la Parte II de la Ética, explica la identidad del orden y conexión de la ideas y de las cosas que ella produce: "El orden y conexión de las ideas es el mismo que el orden y conexión de las cosas" ( $E, G, I I, 89)$; proposición que Spinoza demuestra invocando el axioma 4 de la Parte I -que junto con el resto de los axiomas del inicio de la Ética, conforman el sentido spinoziano preciso de la afirmación tradicional de que conocer es conocer por la causa: la idea de cualquier cosa causada depende del conocimiento de la causa cuyo efecto es. Así, aquello que por su propia potencia se distingue y se diferencia (la causa de sí), se distingue como causalidades (órdenes de causas y efectos) distintas, ellas mismas productoras de nuevas diferencias (modos con potencia propia de producir efectos determinados) al infinito-. De esta manera, la unicidad substancial se determina con precisión, articulando distinciones reales y distinciones modales, como conexión compleja o identidad de una infinidad de órdenes causales diferenciados, que explican la diversidad infinita que la naturaleza produce.

\section{Bibliografía}

Chaui, Marilena (1999). A nervura do real. Imanência e liberdade em Espinosa. T. I. São Paulo: Companhia das Letras.

Deleuze, Gilles (1996). Spinoza y el problema de la expresión, trad. por Horst Vogel. Barcelona: Muchnik Editores.

Descartes, René (1995). Los principios de la filosofía, trad. por Guillermo Quintás. Madrid: Alianza.

Gueroult, Martial (1968). Dieu (Éthique I). París: Aubier-Montaigne.

- (1970). Études sur Descartes, Spinoza, Malebranche et Leibniz. New York: Georg Olms Verlag.

Martínez Martínez, Francisco José (1988). Materialismo, idea de totalidad $y$ método deductivo en Espinosa. Madrid: UNED.

- (2010). Autoconstitución y libertad. Ontología y política en Espinosa III. Respuesta a la crisis del Barroco. Eikasia. Revista de filosofía, No 30, pp. 23-169. 
Negri, Toni (1993). La anomalía salvaje, trad. por G. de Pablo. Barcelona: Anthropos.

Spinoza, Baruch (1984). Ética demostrada según el orden geométrico, trad. por Vidal Peña. Madrid: Editora Nacional.

- (1988). Tratado de la reforma del entendimiento / Principios de Filosofía de Descartes / Pensamientos Metafísicos, trad. por Atilano Domínguez. Madrid: Alianza.

- (1972). Spinoza Opera. Im Auftrag der Heidelberger Akademie der Wissenschaft herausgegeben von Carl Gebhardt. Heidelberg: Carl Winters Universitätsbuchhandlung, 4 Vol.

SuÁreZ, Francisco (1960-1967). Disputaciones metafisicas, 7 vols. Madrid: Gredos.

Tosel, André (1994). Du matérialisme de Spinoza. París: Kimé.

Vidal Peña (1974). El materialismo de Spinoza. Madrid: Revista de Occidente.

Recibido: 22/08/2017

Aceptado: 5/02/2018

\section{@) $(0 \Theta \Theta$}

ENDOXA está bajo una licencia de Creative Commons ReconocimientoNoComercial-SinObraDerivada 4.0 Internacional. 
